\title{
Performance evaluation of two pot raised mud improved cookstove
}

\author{
Hari Bahadur Darlami ${ }^{a, *}$, Bhakta Bahadur Ale ${ }^{a}$ and Govind Raj Pokharel ${ }^{b}$ \\ ${ }^{a}$ Institute of Engineering, Pulchwok Campus, Tribhuvan University, Lalitpur, Nepal \\ ${ }^{b}$ Institute of Engineering, Thapathali Campus, Tribhuvan University, Kathmandu, Nepal
}

\section{ARTICLE INFO}

Article history:

Received 23 Dec 2020

Received in revised form

26 Jan 2021

Accepted 06 Feb 2021

Keywords:

Cookstove

Efficiency

Total emission

Fugitive emission

Thermal performance

\begin{abstract}
Biomass cookstove is widely used in the rural areas of Nepal for cooking and space heating. Its thermal and emission performance keeps importance environmentally, economically and socially. Chimney operated two pot raised mud Improved Cookstove (ICS) is one of Nepal's most promoted cookstoves. The goal of this study is to evaluate the thermal and emission performance. Thermal and emission performance has been obtained by water boiling test and emission parameters have been measured by using Laboratory Emissions Monitoring System (LEMS). The thermal efficiency of cookstove has been improved from $17.99 \%$ to 24.7 $\%$ i.e. Tier 1 to 2 with the fabrication of appropriate material and accessories. Similarly total emission performance has been found in Tier 1 and fugitive emission performance has been found in Tier 5. Experimental results of thermal efficiency and fugitive emission complied with the performance target of the cookstove.
\end{abstract}

\section{Introduction}

Biomass is one of the readily available sources of renewable energy that has long been used for the purpose of cooking and space heating. In the context of Nepal. About $60.9 \%$ of Nepalese people are using fuelwood for cooking purposes [1]. By enhancing thermal efficiency and combustion performance, the use of improved cookstove can reduce energy consumption, contribute to environmental aspects and human health [2]. By improving the thermal efficiency of cookstove and by optimally using the biomass fuel, fuelwood consumption and subsequent environmental pollution can be reduced [3]. Around 1.3 million improved cookstoves have been disseminated to date, and about 2 million people are still using traditional cookstove.

Thermal efficiency can be increased by using appropriate chimney in the cookstove for draft and to reduce indoor air pollution $[4,5]$, optimum combustion chamber height for complete combustion [6], optimum side

\footnotetext{
*Corresponding author:

@ haridarlami@ioe.edu.np (H.B. Darlami)
}

CJIEE Thapathali Campus, IOE, TU. All rights reserved

opening for air fuel mixture inlet [7], size of interconnecting tunnel to create the turbulence of the inflowing air [7], better thermal properties and structural strength [8] .

The primary air entering through the grate is heated by the char and ash which results in better combustion and increases thermal efficiency of the coostove [9]. The thermal efficiency of the cookstove can be improved by garte from $3 \%$ to $5 \%$ [10].

Cookstoves have multiple advantage such as carbon credits, their contribution to climate-change mitigation as well as yield significant co-benefits in terms of energy access for the pro poor people. Furthermore, they can result in improved rural health, environmental, agricultural and economic benefits [11].

Most of the people are using traditional cookstove which has low thermal efficiency and emission performance. It is affecting adversely economic, environmental and human health. So, thermal and emission performance keeps importance for promotion of better cookstove in the rural area. 
The objective of this paper is to test thermal efficiency performance and emission performance.

\section{Materials and methods}

This includes performance test of existing cookstove, its dimensional modification (i.e. the height of combustion chamber, the height of chimney, the area of interconnecting tunnel, the opening), use of $2 \mathrm{~cm}$ grate and use of insulation in the interior surface of combustion chamber. During performance test, thermal and emission performance have been measured.

Thermal efficiency test of cookstove has been done by water boiling test of version 4.2.3.

Cookstove's performance test has been done by water boiling test at Renewable Energy Test Station Lab, Khumaltar Lalitpur.

Thermal efficiency of cookstove has been performed by high power test with certain deviation. In this process, water has been heated for one hour time with feeding constant fuelwood with using test protocols of Water Boiling Test 4.2.3. version [12]. Constant feeding rate helped to supply constant power supply in the cookstove. Exploring stove performance at both high and low power output provides some indication of how a stove performs in a variety of cooking conditions [13]. An excel sheet provided by Global Alliance for clean cookstove has been used for the calculation of thermal efficiency of cookstove.

During water boiling test, emission parameters have been measured by using Laboratory Emissions Monitoring System (LEMS) manufactured by Aprovecho Research Center. During emission measurement, Carbon monoxide (CO) and Particulate Matter (PM2.5) production per MJ delivered to the pot has been measured. Particulate Matter (PM2.5) has been measured by using gravimetric system which gives a direct measurement of total PM using filter-based sampling. Similarly, leakage emission (Fugitive emission) after removing air from chimney has also been measured.

Clean cooking alliance [14] has developed five indicators thermal efficiency, Carbon Monoxide Emissions (gram/megajoule delivered), Fine Particulate Matter Emissions (milligram/megajoule delivered), Safety score, and durability score from Tier 0 to 5 . Tier 0 represents performance typical of open fires and the simplest cookstoves. Among them, first three indicators has to be determined in laboratory shown in Table 1 .

The Tier performance of cookstove has been obtained by linear interpolation of the data and Tier data provided by Clean Cooking Alliance as shown in Table 1.
Table 1: Voluntary performance target

\begin{tabular}{llll}
\hline Tier & $\begin{array}{l}\text { Thermal } \\
\text { Efficiency }(\%)\end{array}$ & $\begin{array}{l}\text { CO Emissions } \\
\left(\mathrm{g} / \mathrm{J}_{d}\right)\end{array}$ & $\begin{array}{l}\mathrm{PM}_{2.5} \\
\left(\mathrm{mg} / \mathrm{J}_{d}\right)\end{array}$ \\
\hline 5 & $\geqslant 50$ & $\leqslant 3.0$ & $\leqslant 5$ \\
4 & $\geqslant 40$ & $\leqslant 4.4$ & $\leqslant 62$ \\
3 & $\geqslant 30$ & $\leqslant 7.2$ & $\leqslant 218$ \\
2 & $\geqslant 20$ & $\leqslant 11.5$ & $\leqslant 481$ \\
1 & $\geqslant 10$ & $\leqslant 18.3$ & $\leqslant 1031$ \\
0 & $<20$ & $>18.3$ & $>1031$ \\
\hline
\end{tabular}

Performance tests of cookstove have been done for initial dimension coostove, best dimension cookstove with dimension modification in the initial dimension cookstove, use of grate and insulation in best dimension cookstove.

\section{Result and discussion}

\subsection{1 Thermal efficiency and tier performance}

Thermal efficiency of the cookstove is shown in Table 2 under various conditions. Thermal efficiency of initial dimension cookstove have been found $17.99 \%$ i.e. its Tier performance has been found 1.8. Its thermal efficiency has been raised to $22.4 \%$ with dimensional modification i.e. Tier performance 2.24. Its thermal efficiency has been found highest with the use of an insulating layer on the inner surface of combustion chamber cookstove. It thermal efficiency has been found $24.7 \%$ and Tier performance has been found 2.47.

Table 2: Thermal efficiency and Tier of the cookstove

\begin{tabular}{lll}
\hline Stove type & $\begin{array}{l}\text { Thermal } \\
\text { Efficiency (\%) }\end{array}$ & Tier \\
\hline Initial dimension & 17.99 & 1 \\
\hline Best dimension & 22.40 & 2 \\
\hline $\begin{array}{l}\text { Best dimension } \\
\text { with }\end{array}$ & 23.64 & 2 \\
$2 \mathrm{~cm}$ grate & 23.63 & 2 \\
\hline $\begin{array}{l}\text { Best dimension } \\
\text { with }\end{array}$ & \\
insulation & \\
\hline $\begin{array}{l}\text { Best dimension } \\
\text { with insulation } \\
\text { and 2cm grate }\end{array}$ & 24.70 & 2 \\
\hline
\end{tabular}

\subsection{2 Emission result and tier performance}

Emission performance has been measured during thermal efficiency test. In first test, total emission emitted by cookstove has been measured and tabulated in Table 3. The emission of Carbon monoxide per unit of energy supplied to the pot has been found 11.9 to $14.3 \mathrm{~g} / \mathrm{MJ}_{d}$ 
i.e. Tier performance 2. Similarly, $\mathrm{PM}_{2} .5$ emission per unit of energy supplied to the pot has been found 545 to $776 \mathrm{~g} / \mathrm{MJ}_{d}$ i.e. Tier 2 performance.

Table 3: Total emission parameters obtained during experiment

\begin{tabular}{lllll}
\hline Stove type & $\begin{array}{l}\mathrm{CO} \\
\left(\mathrm{g} / \mathrm{MJ}_{d}\right)\end{array}$ & Tier & $\begin{array}{l}\mathrm{PM}_{2.5} \\
\left(\mathrm{mg} / \mathrm{MJ}_{d}\right)\end{array}$ & Tier \\
\hline Initial dimension & 11.9 & 1.94 & 545 & 1.88 \\
\hline Best dimension & 13.4 & 1.72 & 650 & 1.69 \\
\hline $\begin{array}{l}\text { Best dimension } \\
\text { with }\end{array}$ & 14.3 & 1.59 & 676 & 1.65 \\
$\begin{array}{l}\text { 2cm grate } \\
\text { Best dimension } \\
\text { with }\end{array}$ & 12.3 & 1.88 & 550 & 1.87 \\
insulation & & 1.76 & 650 & 1.69 \\
\hline $\begin{array}{l}\text { Best dimension } \\
\text { with insulation } \\
\text { and 2cm grate }\end{array}$ & 13.1 & & & \\
\hline
\end{tabular}

In second test, only leakage emission (Fugitive emission) after passing flue gas from chimney been measured and tabulated in Table 4. Carbon monoxide emission per unit of energy supplied to the pot has been found 0.09 to $0.11 \mathrm{~g} / \mathrm{MJ}_{d}$ which lies in Tier 5 performance. Similarly, $\mathrm{PM}_{2.5}$ emission per unit of energy supplied to the pot has been found to be 4 to $5 \mathrm{mg} / \mathrm{MJ}_{d}$ which lies in Tier 5 performances which meets the quality of indoor pollution. So, after removal of exhausted gas through chimney, kitchen performance has been improved. In the absence of chimney, total emission total emission will be more than standard. So, leakage emission from cookstove may cause indoor pollution.

Table 4: Indoor emission parameters obtained during experiment

\begin{tabular}{lllll}
\hline Stove type & $\begin{array}{l}\mathrm{CO} \\
\left(\mathrm{g} / \mathrm{MJ}_{d}\right)\end{array}$ & Tier & $\begin{array}{l}\mathrm{PM}_{2.5} \\
\left(\mathrm{mg} / \mathrm{MJ}_{d}\right)\end{array}$ & Tier \\
\hline Initial dimension & 0.11 & 5 & 4 & 5 \\
\hline Best dimension & 0.11 & 5 & 5 & 5 \\
\hline $\begin{array}{l}\text { Best dimension } \\
\text { with }\end{array}$ & 0.11 & 5 & 5 & 5 \\
2cm grate & 0.09 & 5 & 5 & 5 \\
\hline $\begin{array}{l}\text { Best dimension } \\
\text { with } \\
\text { insulation }\end{array}$ & & 5 & 4 & 5 \\
\hline $\begin{array}{l}\text { Best dimension } \\
\text { with insulation } \\
\text { and 2cm grate }\end{array}$ & 0.09 & 5 & \\
\hline
\end{tabular}

\subsection{Comparison of tier performance}

Thermal efficiency, total and fugitive $\mathrm{CO}$ and PM emissions have been compared.

Thermal efficiency and total emission performance com-

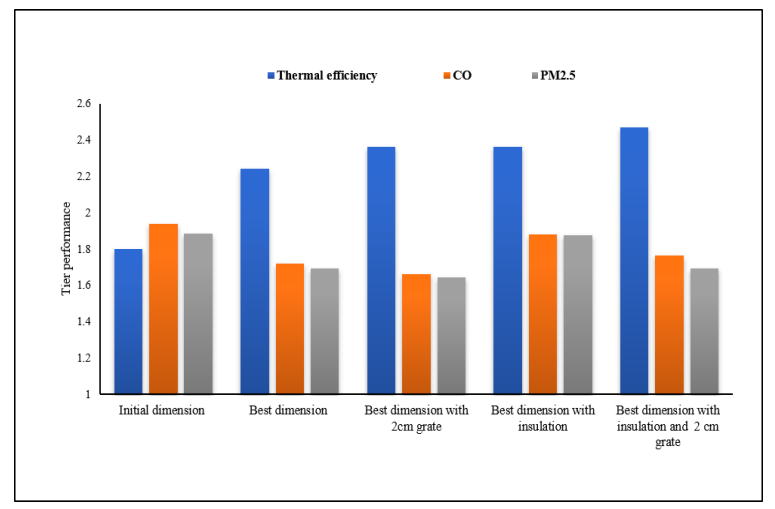

Figure 1: Thermal efficiency and total emission comparison

parison shown in Figure 1. The thermal efficiency of existing cookstove has been found lowest tier in initial dimension and in increasing trend with fabrication in appropriate dimension, material and accessories. In this type of cookstove, it has been found that $\mathrm{CO}$ emission is better than PM emission in all cases. In best dimension cookstove, thermal performance has been increased but emission performance has been decreased. This is due to decrease of combustion chamber height, this results reduction of height for flame development. With the use of grate in best dimension, thermal performance has been increased but emission performance has been decreased. This is due to further reduction in height between the bottom surface of the pot and bed of the cookstove. With the implementation of insulating layer in the combustion chamber, thermal and emission performance has been improved. This is due to increase of temperature of combustion chamber which results better pyrolysis and complete combustion. Thermal performance has been found to be more enhanced with the use of insulation layer and grate of $2 \mathrm{~cm}$ thickness, but emission performance has been found to be almost the same as best dimension cookstove. In all cases, $\mathrm{CO}$ and $\mathrm{PM}$ emission are in same trend which is also observed by Agenbroad [5].

Thermal and fugitive emission performance comparison shown in Figure 2. In all cases, thermal efficiency performance has been increased gradually and emission performance has been increased to highest rank Tier 5. This meets the requirement for indoor pollution of kitchen

After use of chimney, flue gas has been removed to outside and only leakage cause emission in the room. Comparison of CO and PM2.5 emission between total emission and fugitive emission shown in Figure 3. This shows that fugitive emission has been found within the standard. Kumar et al also concluded that chim- 


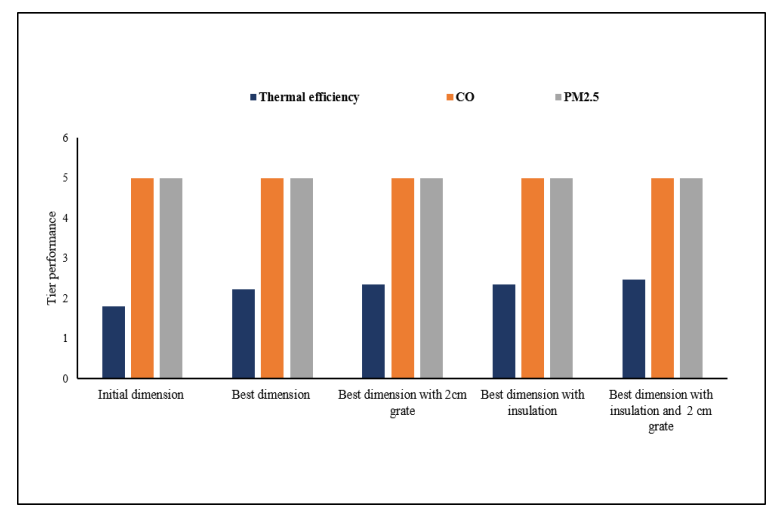

Figure 2: Thermal efficiency and fugitive emission comparison

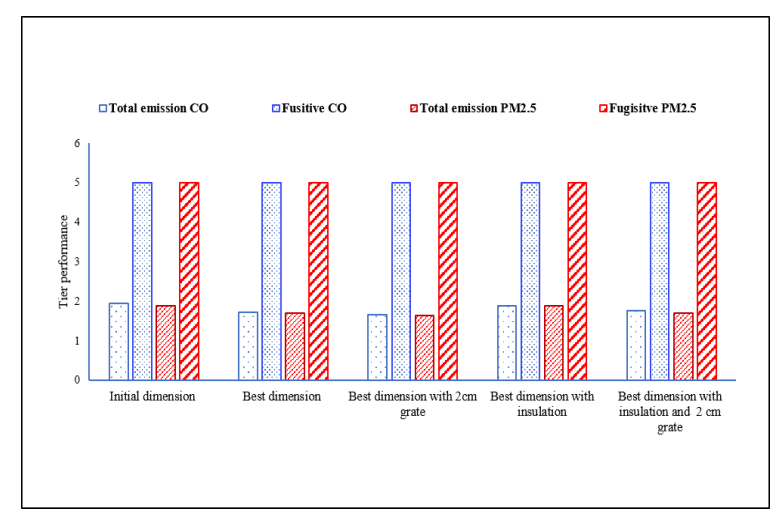

Figure 3: Comparison of total and fugitive emission

ney cookstove significantly reduced human exposure to hazardous combustion products including particulate matter (PM) and CO [15].

\section{Conclusions}

The results from the study are below.

$\mathrm{i}$ The thermal efficiency of cookstove has been increased from $17.99 \%$ to $24.7 \%$ i.e. Tier 1 to 2 with fabrication of appropriate dimension, material and accessories.

ii Total $\mathrm{CO}$ and $\mathrm{PM}_{2.5}$ ranges have been found 11.9 to $14.3 \mathrm{~g} / \mathrm{MJ}_{d}$ and 545 to $676 \mathrm{mg} / \mathrm{MJ}_{d}$ respectively which lies in Tier 2 performance.

iii Indoor $\mathrm{CO}$ and $\mathrm{PM} 2.5$ ranges have been found 0.09 to $0.11 \mathrm{~g} / \mathrm{MJ}_{d}$ and 4 to $5 \mathrm{mg} / \mathrm{MJ}_{d}$ respectively which lies in Tier 5 performance.

iv Thermal efficiency and fugitive emission performance can be increased with appropriate dimension, material and accessories.

\section{Acknowledgement}

The authors gratefully acknowledge the Department of Mechanical Engineering, Pulchowk Campus and Renewable Energy Test Station, Khumaltar, Lalitpur for their continuous support. Finally, we would like to thank the editor and all reviewers for their supportive and incisive comments.

\section{References}

[1] Bureau C, Statistics O F. Annual household survey 2015/16[J]. 2016, 16.

[2] Smith K. Health,energy, and green house-gas impacts of biomass combustion in household stoves[J]. .Energy Sustainable Development, 1994.

[3] Sedighi M, Salarian H. A comprehensive review of technical aspects of biomass cookstoves[J/OL]. Renewable and Sustainable Energy Reviews, 2017, 70: 656-665. DOI: https: //doi.org/10.1016/j.rser.2016.11.175.

[4] Prapas J, Baumgardner M E, Marchese A J, et al. Influence of chimneys on combustion characteristics of buoyantly driven biomass stoves[J/OL]. Energy for Sustainable Development, 2014, 23: 286-293. DOI: https://doi.org/10.1016/ j.esd.2014.08.007.

[5] Agenbroad J, DeFoort M, Kirkpatrick A, et al. A simplified model for understanding natural convection driven biomass cooking stoves-Part 2: With cook piece operation and the dimensionless form[J/OL]. Energy for Sustainable Development, 2011, 15(2): 169-175. DOI: https://doi.org/10.1016/ j.esd.2011.04.002.

[6] Bussmann P. P K. Parameter analysis of a simple wood burning cook stove. In: Proceedings of M. Sedighi, H. Salarian Renewable and Sustainable Energy Reviews 70, 656-665 International Heat Transfer Conference. San Francisco; 1986 p. 3085-3090.[J]. International Heat Transfer Conference. San Francisco, 2017: 3085-3090.

[7] Sharma S K. Improved Solid Biomass Burning Cookstoves: a Development Manual[J]. Asia Regional Cookstove Programme and Energy Research Centre of Panjab University, Chandigarh, 1993: 125.

[8] J. K. Kumar R L S. Development, analysis and dissemination of a three pan cook stove. Bangalore: Indian Institute of Science[J]. 1990.

[9] Sutar K B, Kohli S, Ravi M R, et al. Biomass cookstoves: A review of technical aspects[J/OL]. Renewable and Sustainable Energy Reviews, 2015, 41: 1128-1166. DOI: https://doi.org/ 10.1016/j.rser.2014.09.003.

[10] Gusain P. Cooking energy in India. Development Alternatives,[J]. Vikas Publishing House Pvt. Ltd.;. New Delhi: India, 1990.

[11] Gill J. Improved stoves in developing countries. A critique[J/OL]. Energy Policy, 1987, 15(2): 135-144. DOI: https://doi.org/10.1016/0301-4215(87/90121-2.

[12] PCIA \& Global Alliance. The Water Boiling Test Version 4.1.2; Cookstove Emissions and Efficiency in a Controlled Laboratory Setting[J/OL]. Glob. Alliances Clear. cookstoves, 2013, 2. http://www.aprovecho.org/lab/pubs/testing.

[13] Bailis R, Berrueta V, Chengappa C, et al. Performance testing for monitoring improved biomass stove interventions: experiences of the Household Energy and Health Project This paper is one of six describing work done as part of the Household Energy and Health (HEH) Project[J/OL]. Energy for Sustainable Development, 2007, 11(2): 57-70. DOI: https: //doi.org/10.1016/S0973-0826(08/60400-7.

[14] Clean Cooking Alliance. Voluntary Performance 
Performance evaluation of two pot raised mud improved cookstove

Targets[M/OL]// clean cooking alliance. https: //www.cleancookingalliance.org/about/news/10-16-2018-

voluntary-performance-targets.html.

[15] Manoj Kumar, Sachin Kumar, Tyagi S K. Design, development and technological advancement in the biomass cookstoves: A review[J/OL]. Renewable and Sustainable Energy Reviews, 2013, 26: 265-285. DOI: https://doi.org/10.1016/j.rser.2013.05.010. 